\title{
The role of emergency physicians in tobacco cessation and British Columbia's Smoking Cessation Program
}

\author{
Kai Wai Cheung, MD, MPH
}

Even though media coverage has focused on public health issues such as the alarming increase in obesity, tobacco smoke remains a leading cause of preventable deaths in Canada. ${ }^{1}$ In 2011, the Canadian Tobacco Use Monitoring Survey reported that approximately 5 million Canadians 15 years of age and over were smokers. ${ }^{2}$ A much larger proportion of the Canadian population is exposed to known carcinogens through second-hand smoke. Each year, approximately 37,000 Canadians die as a result of tobacco smoke. ${ }^{3}$ Smoking also causes significant morbidity, resulting in chronic health conditions requiring frequent emergency department (ED) visits and hospitalizations. In Canada, the financial burden of tobacco is $\$ 17$ billion a year, including $\$ 4.4$ billion a year in direct health care costs. ${ }^{3}$

Over the years, much has been done to control the Canadian tobacco pandemic, including increasing tobacco prices and taxes, establishing policies mandating smoke-free public premises, and restrictions in advertising. In British Columbia, the Ministry of Health introduced a provincial smoking cessation program in September 2011.4 Available to all BC residents, this program offers either free nonprescription nicotine replacement therapies (NRTs) for smokers or partially subsidized smoking cessation prescription medications for eligible smokers. The two medications covered are bupropion (Zyban) and varenicline (Champix). Individuals access the program by calling 8-1-1 and are provided with either an NRT or the prescription medication for up to 12 weeks each calendar year, dispensed as a 28-day supply each time. Although a recent study has questioned the effectiveness of NRTs, ${ }^{5}$ meta-analyses have shown that NRTs double the rate of smoking cessation at 6 months, ${ }^{6,7}$ whereas varenicline $^{8}$ and bupropion ${ }^{9}$ both increase quit rates by slightly more than 2 times at 6 months when compared to placebo. Currently, medication subsidy programs are also in place in the Northwest Territories, Ontario, Alberta, Saskatchewan, and Quebec.

In British Columbia, there are approximately 550,000 smokers. ${ }^{1}$ In the 12 months after introduction of the B.C. Smoking Cessation Program, almost 150,000 orders were placed for free NRTs and over 40,000 smokers had received subsidies for smoking cessation prescription medications. ${ }^{10}$ These numbers demonstrate that many people want to quit smoking and are looking for assistance to do so.

As part of a current randomized controlled trial (NCT01454375) in our ED at Vancouver General Hospital (VGH), we have been collecting data on the use of NRTs as well as bupropion and varenicline in the ED smoking population. VGH is a tertiary care teaching hospital that serves an urban population, with the ED seeing more than 80,000 patients annually. Although there has been a positive uptake of the B.C. Smoking Cessation Program among the general population of smokers in British Columbia, this uptake has not reached the ED population. In the 12 months since the introduction of the program, the use of smoking cessation aids in this study population from

From the Department of Emergency Medicine, Vancouver General Hospital, and Faculty of Medicine, University of British Columbia, Vancouver, BC.

Correspondence to: Dr. Ka Wai Cheung, Department of Emergency Medicine, Vancouver General Hospital, 855 West 12 th Avenue, Vancouver, BC V5Z 1M9; tokwcheung@gmail.com.

This article has been peer reviewed.

(C) Canadian Association of Emergency Physicians

CJEM 2014;16(2):89-90

DOI 10.2310/8000.2013.131065 
the VGH ED has remained low, with approximately $6 \%$ using NRTs and less than $1 \%$ using bupropion or varenicline.

The ED population represents a high-risk group, with a higher prevalence of smoking than the general population. ${ }^{11}$ Many in the ED population may have less access to health care services, for example, family physicians. Increasingly, EDs are becoming the "safety net" for the entire health care system, ${ }^{11}$ and as a result, the ED visit may be the only opportunity for these patients to be connected to community health programs. Importantly, smokers who receive counselling while sick are more likely to quit smoking than those who receive counselling while well, a phenomenon known as the "teachable moment." ${ }_{12}$ Finally, ED smokers want to quit; one ED study demonstrated that about $70 \%$ of smokers desire to quit smoking and almost $50 \%$ want to quit within 1 month. ${ }^{13}$

Emergency staff therefore have the opportunity to play a crucial role in tobacco cessation interventions and in connecting patients to vital community health programs. Smoking cessation interventions are costeffective, even more so than routine clinical practices such as lowering low-density lipoprotein cholesterol and blood pressure control. ${ }^{14}$ At present, ongoing research is being conducted on optimizing methods to screen and counsel ED smokers. Unfortunately, not only are ED patients unaware of community resources, but emergency staff may also be unaware. If the ED population were reached, increasing quit rates with NRTs and other medications may lead to significantly reduced tobaccorelated morbidity and mortality and substantial cost savings. Emergency staff can play a critical role in smoking cessation interventions, and further research is urgently needed to optimize methods of increasing ED staff awareness of community programs and connecting ED patients to these resources.

Keywords: emergency department, nicotine replacement therapy, tobacco

Competing interests: None declared.

\section{REFERENCES}

1. Propel Centre for Population Health Impact. Tobacco use in Canada: patterns and trends - 2012 edition. Available at: www. tobaccoreport.ca/2012 (accessed January 15, 2013).
2. Health Canada. 2011 Canadian Tobacco Use Monitoring Survey. Available at: http://www.hc-sc.gc.ca/hc-ps/tobactabac/research-recherche/stat/ctums-esutc_2011-eng.php (accessed January 10, 2013).

3. Canadian Public Health Association. Canadian Public Health Association position paper. The winnable battle: ending tobacco use in Canada. December 2011. Available at: http://www.cpha. ca/uploads/positions/position-paper-tobacco_e.pdf (accessed January 15, 2013).

4. British Columbia Ministry of Health. B.C. Smoking Cessation Program. 2011. Available at: http://www.health.gov.bc.ca/ pharmacare/stop-smoking/ (accessed January 15, 2013).

5. Alpert HR, Connolly GN, Biener L. A prospective cohort study challenging the effectiveness of population-based medical intervention for smoking cessation. Tobacco Control 2013;22:32-7, doi:10.1136/tobaccocontrol-2011-050129.

6. Moore D, Aveyard P, Connock M, et al. Effectiveness and safety of nicotine replacement therapy assisted reduction to stop smoking: systematic review and meta-analysis. BMF 2009;338:867-79, doi:10.1136/bmj.b867.

7. Eisenberg MJ, Filion KB, Yavin D, et al. Pharmacotherapies for smoking cessation: a meta-analysis of randomized controlled trials. CMA7 2008;179:135-44, doi:10.1503/ cmaj.070256.

8. Cahill K, Stead LF, Lancaster T. Nicotine receptor partial agonists for smoking cessation [update appears in Cochrane Database Syst Rev 2010;(12):CD006103]. Cochrane Database Syst Rev 2008;(3):CD006103.

9. Hughes J, Stead L, Lancaster T. Antidepressants for smoking cessation [update appears in Cochrane Database Syst Rev 2007;(1):CD000031]. Cochrane Database Syst Rev 2004;(4):CD000031.

10. BC Government Online News Source. Newsroom. Celebrating the anniversary of the Smoking Cessation Program. October 12, 2012. Available at: http://www.newsroom.gov. bc.ca/2012/10/celebrating-the-anniversary-of-the-smokingcessation-program.html (accessed January 15, 2013).

11. Cummings GE, Francescutti LH, Predy G, et al. Health promotion and disease prevention in the emergency department: a feasibility study. CFEM 2006;8:100-5.

12. Bernstein SL, Becker BM. Preventive care in the emergency department: diagnosis and management of smoking and smoking-related illness in the emergency department: a systematic review. Acad Emerg Med 2002;9:720-9, doi: 10.1111/j.1553-2712.2002.tb02153.x.

13. Lowenstein SR, Tomlinson D, Koziol-McLain J, et al. Smoking habits of emergency department patients: an opportunity for disease prevention. Acad Emerg Med 1995; 2:165-71, doi:10.1111/j.1553-2712.1995.tb03189.x.

14. Kahn R, Robertson RM, Smith R, et al. The impact of prevention on reducing the burden of cardiovascular disease. Circulation 2008;118:576-85, doi:10.1161/CIRCULATIONAHA. $\underline{108.190186 .}$ 